\title{
PULMONARY HYPERTENSION DUE TO LEFT HEART DISEASE
}

\author{
S. Jahangeer Basha, G. Deepthi
}

\begin{abstract}
:
The most common cause of pulmonary hypertension is left heart disease, arising in response to increased left ventricular or left a trial filling pressures[1,2,3]. During the 5th World Symposium held in Nice, France, in 2013, the consensus was reached to maintain the general scheme of previous clinical classifications, placing the Pulmonary Hypertension due to left heart disease in Group 2 [4].PH is defined by a mean pulmonary arterial pressure $>25 \mathrm{mmHg}$. In the case of $\mathrm{PH}$ associated with LHD, this is associated with a pulmonary capillary wedge pressure $>15 \mathrm{mmHg}$ or left ventricular enddiastolic pressure (LVEDP) > $18 \mathrm{~mm} \mathrm{Hg} \mathrm{[1,5].Pulmonary}$ hypertension due to left-sided heart disease is associated with higher morbidity and mortality [6,7,8].This study is done to know the pattern of clinical presentation of pulmonary hypertension and to see the gender difference.
\end{abstract}

\section{INTRODUCTION}

The most common cause of pulmonary hypertension is left heart disease, arising in response to increased left ventricular or left a trial filling pressures [1,2,3]. During the 5th World Symposium held in Nice, France, in 2013, the consensus was reached to maintain the general scheme of previous clinical classifications, placing the Pulmonary Hypertension due to left heart disease in Group 2 [4].PH is defined by a mean pulmonary arterial pressure $>25 \mathrm{mmHg}$. In the case of $\mathrm{PH}$ associated with LHD, this is associated with a pulmonary capillary wedge pressure $>15 \mathrm{mmHg}$ or left ventricular enddiastolic pressure (LVEDP) $>18 \mathrm{~mm} \mathrm{Hg}$ [1,5].Pulmonary hypertension due to left-sided heart disease is associated with higher morbidity and mortality $[6,7,8]$. This study is done to know the pattern of clinical presentation of pulmonary hypertension and to see the gender difference.

Article received on 5 July 2016, published on 30 July 2016.

S.Jahangeer Basha ${ }^{1}$, G.Deepthi ${ }^{2}$

${ }^{1,2}$ Resident, Department of Cardiology, NIMS, India

Corresponding author: S.Jahangeer Basha

Email: jahangeer2k3@gmail.com

\section{MATERIALS \& METHODS}

We have retrospectively analyzed the data of 208 patients presenting with various cardiac diseases to the Nizam's Institute of Medical Sciences, Hyderabad, India between April 2015 to March 2016. The diseases include left sided valvular heart diseases and cardiomyopathies. Left sided valvular heart diseases may be due to single valve or both valves involvement with either stenotic or regurgitant lesions. Cardiomyopathies included dilated or ischemic cardiomyopathies. It was mandatory to have $\mathrm{PH}$ on echocardiography along with the listed left heart diseases. End stage renal, liver failure patients and pregnant females were excluded.

We collected the demographic data including risk factors for CAD, ECG, $X$ - ray chest, 2D echocardiographic details (RV\& LV function, estimated Pulmonary Arterial Systolic Pressure - PASP, valvular morphology), basal lab parameters and cardiac catherization data if done.

\section{RESULTS}

Out of 208 patients, 40 were females with mean age of 51.83 years and 168 were males with mean age of 53.32 years. Male and female $\mathrm{PH}$ patients due to left heart diseases were in $6^{\text {th }}$ decade. Risk factors and severity of $\mathrm{PH}$ were comparable between the male and female patients (Table 1). Severe $\mathrm{PH}$ constituted about $17 \%$ in both male and female patients.

Table 1: Demographic and PH severity details in both sexes.

\begin{tabular}{|l|l|l|l|}
\hline Parameter & Male & Female & p Value \\
\hline Number & 168 & 40 & \\
\hline Age & $53.3 \pm 14.5$ & $51.8 \pm 12.9$ & 0.55 \\
\hline HTN & $81(48.2 \%)$ & $19(47.5 \%)$ & 0.93 \\
\hline DM & $56(33.3 \%)$ & $17(42.5 \%)$ & 0.29 \\
\hline Severity of PH & $73(43.4 \%)$ & $22(55 \%)$ & 0.19 \\
\hline Mild & $65(38.7 \%)$ & $11(27.5 \%)$ & 0.16 \\
\hline Moderate & $30(17.9 \%)$ & $7(17.5 \%)$ & 0.95 \\
\hline Severe &
\end{tabular}


In females, valvular disease was more frequently associated with $\mathrm{PH}$, whereas in males it was LV disease with significant $\mathrm{p}$ values $(\mathrm{p}=0.05, \mathrm{p}=0.02$ respectively) (Table 2).

Table 2: Details of Causes of Left Heart Disease.

\begin{tabular}{|c|c|c|c|}
\hline Variables & Male & Female & $\begin{array}{l}\mathrm{p} \\
\text { value }\end{array}$ \\
\hline $\begin{array}{l}\text { Valvular } \\
\text { disease }\end{array}$ & $\begin{array}{l}25(\text { mitral + } \\
\text { aortic }=4, \\
\text { mitral=21) } \\
(14.9 \%)\end{array}$ & $\begin{array}{l}12(\text { mitral + aortic } \\
=5, \text { mitral }=7) \\
(30 \%)\end{array}$ & 0.05 \\
\hline $\begin{array}{l}\mathrm{LV} \\
\text { disease }\end{array}$ & 129 (76.8\%) & $23(57.5 \%)$ & 0.02 \\
\hline
\end{tabular}

There was no difference in the presence of LV dysfunction in between male and female $\mathrm{PH}$ patients ( $\mathrm{p}$ $=0.56$ ), but severe LV dysfunction leading to PH is more common in males $(\mathrm{p}=0.001)$. Even $\mathrm{RV}$ dysfunction was more prevalent in males $(27.4 \%$ vs $10 \%, \mathrm{p}=0.003)$. (Table 3, Fig 1).

Table 3: 2D Echo features in the study population

\begin{tabular}{|l|l|l|l|}
\hline Echo Variables & Male & Female & $\mathrm{p}$ value \\
\hline $\begin{array}{l}\text { Severity of Left } \\
\text { ventricular } \\
\text { Dysfunction }\end{array}$ & $116(69.1 \%)$ & $21(52.5 \%)$ & 0.56 \\
\hline Mild & $9(5.3 \%)$ & $2(5 \%)$ & 0.9 \\
\hline Moderate & $20(11.9 \%)$ & $9(22.5 \%)$ & 0.13 \\
\hline Severe & $87(51.8 \%)$ & $10(25 \%)$ & 0.001 \\
\hline $\begin{array}{l}\text { Presence of } \\
\text { Right ventricular } \\
\text { Dysfunction }\end{array}$ & $46(27.4 \%)$ & $4(10 \%)$ & 0.003 \\
\hline
\end{tabular}

Fig 1: Bar diagram depicting the more severe LV and RV dysfunction in male PH-LVH patients.

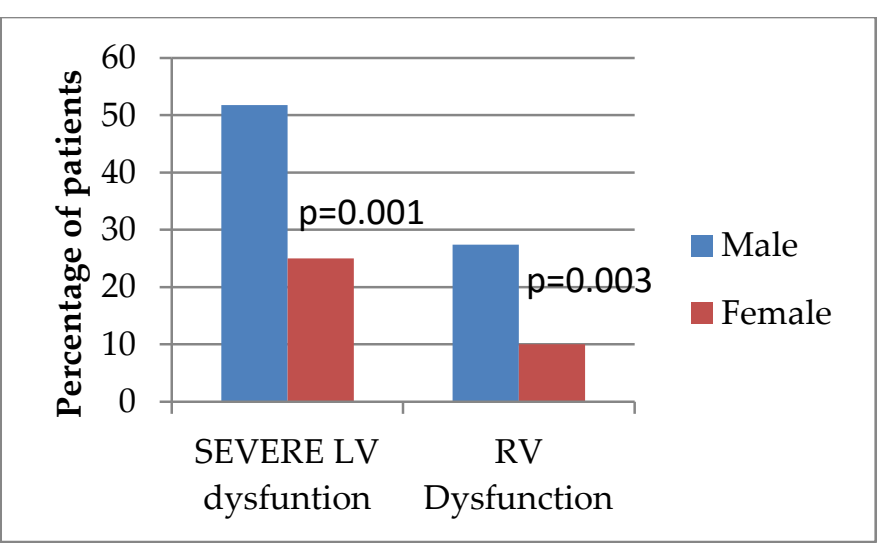

Out of 40 females, 35 patients underwent cardiac catheterization and out of 168 males, 87 patients underwent cardiac catheterization (Fig 2). Cath wise PH presence and its severity were correlated with 2D Echo.

Fig 2: Cardiac catheterization details.

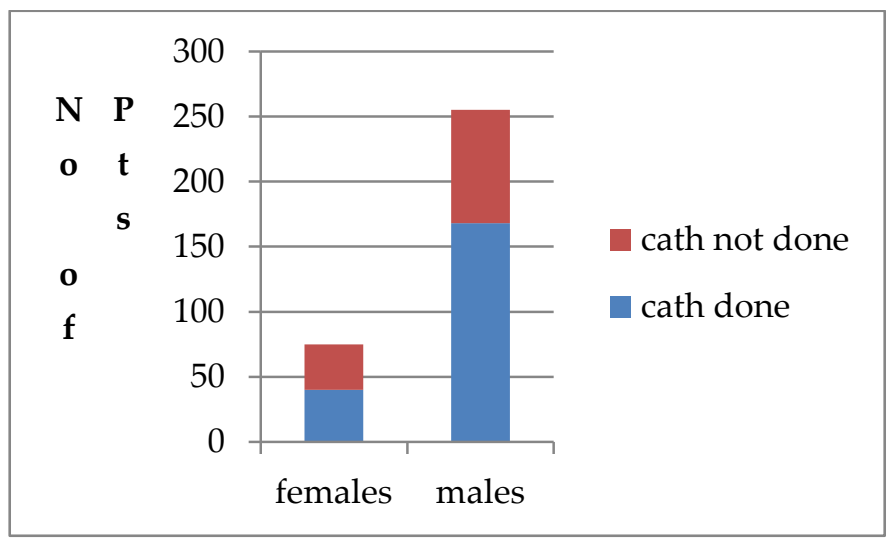

Table 4- Catheterization details

\begin{tabular}{|l|l|l|l|}
\hline Patients & $\begin{array}{l}\text { PASP } \\
(\mathrm{mm} \mathrm{Hg})\end{array}$ & $\begin{array}{l}\text { Mean } \\
\text { PAP }(\mathrm{mm} \mathrm{Hg})\end{array}$ & $\begin{array}{l}\text { PCWP } \\
(\mathrm{mmHg})\end{array}$ \\
\hline MALES & $48 \pm 15$ & $25 \pm 4$ & $32 \pm 5$ \\
\hline FEMALES & $46 \pm 15$ & $22 \pm 4$ & $28 \pm 4$ \\
\hline
\end{tabular}

\section{DISCUSSION:}

Pulmonary hypertension is the manifestation of many cardiac diseases. Left sided heart disease is the most common cause of pulmonary hypertension. The pathophysiological events underlying the development of pulmonary hypertension in left heart disease are elevated LV filling pressures, pulmonary venous hypertension and pulmonary arteriolar vasoconstriction [9]. We have to pay attention for the presence and severity of $\mathrm{PH}$, as it is associated with poor prognosis.

PH is considered mild if the echo- estimated PASP is 35 to $45 \mathrm{~mm} \mathrm{Hg}$, moderate if it is 46 to $60 \mathrm{~mm} \mathrm{Hg}$, and severe when $>60 \mathrm{~mm} \mathrm{Hg}$ [10]. The primary causes of $\mathrm{PH}-$ LHD are left ventricular dysfunction of systolic and diastolic origin and valvular disease $[3,11,12,13]$. In our series we have seen these etiologies as the cause for PH.

In our study, all patients admitted in the Department of Cardiology, Nizam's Institute of Medical Sciences, Hyderabad, India between April 2015 to March 2016 
were screened and 208 patients were found to have pulmonary hypertension due to left heart disease. The relative frequency of pulmonary hypertension is more in males $(80.76 \%)$ than in females $(19.24 \%)$. The mean age at presentation was similar in both males and females (53.32 years in males, 51.83 years in females).

As the mitral valve disease is more common in females [14], in our series also valvular diseases responsible for $\mathrm{PH}$ is more in females with $\mathrm{p}$ value of 0.05 . The incidence of associated hypertension was similar in males $(48.2 \%)$ compared to females $(47.5 \%)$. The incidence of associated diabetes was more in females $(42.5 \%)$ compared to males (33.3\%).Majority of the patients had mild to moderate $\mathrm{PH}$. Severe $\mathrm{PH}$ was present in only $37(17.7 \%)$ patients.

The most common cause of pulmonary hypertension in our study is left ventricular disease $(74.4 \%$ males and $55 \%$ females) which is due to coronary artery disease and dilated cardiomyopathy. The second most common cause observed is valvular heart disease. The relative frequency of valvular heart disease is more in females (30\%) compared to males (14.9\%). Most common etiology of valvular heart disease is chronic rheumatic heart disease followed by degenerative valvular disease. The results are similar to those obtained by Tatsurolbe et al. [15]

In our study, most of the patients had LV dysfunction. LV dysfunction is more common in males and majority of them had severe LV dysfunction. RV dysfunction is also more common in males $(27.4 \%)$ compared to females $(10 \%)$.

\section{LIMITATIONS}

This is a retrospective and small sample study in a single tertiary center. The patients who were hospitalized in our center might be highly selected. So, there is selection bias. Diastolic dysfunction of LV is one of the important causes of PH secondary to left heart disease, but it is not differentiated from systolic dysfunction in our study.

\section{CONCLUSIONS}

The most common cause of $\mathrm{PH}$ secondary to left heart disease is LV disease followed by valvular heart disease. Valvular disease is more frequently associated with $\mathrm{PH}$ in females than in males

\section{REFERENCES}

1.Vachiéry JL, Adir Y, Barberà JA, et al. Pulmonary Hypertension Due to Left Heart Diseases. J Am Coll Cardiol.2013; 62:D100-8.

2. Guazzi M, Galie N Pulmonary hypertension in left heart disease. Eur Respir Rev 2012; 21: 126, 338-346.

3.Guazzi M, Arena R. Pulmonary hypertension with left sided heart disease. Nat Rev Cardiol.2010; 7: 648-659.

4. Simonneau G, Gatzoulis MA, Adatia I, et al. Updated clinical classification of pulmonary hypertension. J Am CollCardiol.2013; 62Suppl: D34-41.

5. Fang JC, DeMarco T, Givertz MM, et al. World Health Organization Pulmonary Hypertension Group 2: Pulmonary hypertension due to left heart disease in the adult - a summary statement from the Pulmonary Hypertension Council of the International Society for Heart and Lung Transplantation. J Heart Lung Transplant. 2012; 31:913-33

6. Barnett CF, De Marco T. Pulmonary hypertension associated with left-sided heart disease. Heart Fail Clin 2012; 8:447-59.

7. Kiefer TL, BashoreTM. Pulmonary hypertension related to left sided cardiac pathology. Pulm Med. January 1, 2011; 381787.

8. Yamabe S, Dohi Y, Fujisaki S, et al. Prognostic Factors for Survival in Pulmonary Hypertension Due to Left Heart Disease. Circ. J. January 1, 2016; 80 (1); 2439.

9. Barnett CF, Selby VN. Overview of WHO Group 2 Pulmonary Hypertension Due to Left Heart Disease. Advances in Pulmonary Hypertension. Volume 14, Number 2; 2015. 
10. Guazzi M, Borlaug BA. Pulmonary hypertension due to left heart disease. Circulation 2012; 126: 975-990.

11. Farber HW, Gibbs S. Under pressure: pulmonary hypertension associated with left heart disease. EurRespir Rev. December 1, 2015; 24 (138); 665-73.

12. Adir Y, Amir O. Pulmonary hypertension associated with left heart disease. SeminRespirCrit Care Med. October 1, 2013; 34 (5); 665 -80.
13. Mielniczuk LM. Pulmonary hypertension in left heart disease. Can J Cardiol 2010; 26(Suppl B):24B-26B.

14. Turi ZG. Mitral Valve Disease. Circulation. 2004; 109:e38-e41.

15. Ibe $\mathrm{T}$, Wada $\mathrm{H}$, Sakakura $\mathrm{K}$ et al. Pulmonary hypertension due to left heart disease: The prognostic implications of diastolic pulmonary vascular pressure gradient. Journal of Cardiology 67 (2016) 555-559. 